\title{
A Common Mistake in Design of Water Tank
}

\author{
Gajendra Verma \\ Rajiv Gandhi Technical University, Sri Aurobindo Institute of Technology, Indore Madhya Pradesh (India)
}

\begin{abstract}
In this paper a common mistake in calculating the thickness the wall and corresponding area of reinforcement in the water tank by working stress method have been discussed. Due to water pressure, wall of the water tank is subjected to Tension and Bending Moment. In most of the books, the thickness of the wall and area of reinforcement for bending moment is calculated by following formulae considering cracked section

$$
\begin{aligned}
t & =\sqrt{\frac{M}{R b}}+\text { effective cover and } \\
\text { Ast } t & =\frac{M}{\sigma s t^{*}+d}
\end{aligned}
$$

When the moment of resistance of wall section (which is the least moment of resistance of wall considering as cracked and uncracked section) is calculated from the above values of " $t$ " and "Ast", it comes out less than the applied moment, hence design is not safe. Therefore, it is necessary to determine thickness and corresponding area of reinforcement of wall section in such a manner so that it remains safe in cracked as well as in uncracked condition. To overcome this problem, a simple procedure for calculating the thickness the wall and area of reinforcement in the water tank by working stress method have been discussed. In this paper, the thickness of wall is calculated considering it as an uncracked section ignoring area of reinforcement and area of reinforcement considering it as a cracked section. At the end, effect on area of reinforcement due reduction in thickness of wall of tank have been also discussed.
\end{abstract}

Keywords: Working stress method, Area of reinforcement, Thickness of Wall, Cracked section, Uncracked section

\section{Introduction}

The liquid retaining structures are used to store liquid like water, diesel, petrol etc. A water tank is used to store water to tide over the daily requirements. In general, water tanks can be classified under three heads: (i) tanks resting on ground (ii) elevated tanks supported on staging, and (iii) underground tanks. From the shape point of view, water tanks may be classified as Circular tank, Rectangular tank, Spherical tank and Intze tank. The liquid retaining structures are designed as a crack free structure and hence their designed is different from others R.C.C. structures. For crack free structure, the tensile stresses in concrete calculated on equivalent concrete section should be within permissible limits as given in IS:3370-II-2009. In order to avoid leakage and to impart impermeability to the concrete, concrete of grade M-30 (M-25 for smaller tank up to capacity $<50 \mathrm{~m}^{3}$ ) and above is recommended for liquid retaining structures according to IS: 3370-I-2009.The Indian standard code (IS:3370-I-2009) suggested minimum cement content 320 $\mathrm{kg} / \mathrm{m}^{3}$ in order to have impermeable concrete and to keep shrinkage low. As per the provisions of the code (IS 3370-II2009), the water tanks may be designed by

- Working stress method

- Limit State method

\section{Symbols Used}

$\mathrm{b}=$ Breadth of the section

$\mathrm{t}=$ Overall thickness of the section

$\mathrm{d}=$ Effective depth of the section

$\sigma \mathrm{cbc}=$ Permissible compressive stress in concrete due to bending.

$\sigma \mathrm{cbt}=$ Permissible tensile stress in concrete due to bending.

$\sigma$ st $=$ Permissible stress in steel in tension.

$\mathrm{m}=$ Modular ratio .

$\mathrm{k}=$ Neutral axis depth factor $\mathrm{j}=$ Lever arm factor

$\mathrm{R}=$ Moment of resistance factor

$\mathrm{A}_{\mathrm{T}}=$ Equivalent area of transformed Section

$\mathrm{I}_{\mathrm{T}}=$ Equivalent moment of inertia transformed Section about neutral axis

Ast $=$ Area of steel in tension

$\mathrm{M}=$ Applied bending moment

M.R. = Moment of resistance

Mcr $=$ Moment of resistance of section considering cracked section

Muncr $=$ Moment of resistance of section considering uncracked section

\section{Problem Formulation}

A numerical problem is taken for discussion in which wall of the tank is designed by working stress method for a given bending moment using the procedure given in most of books. Then moment of resistance of wall section is determined considering cracked and uncracked section. It is found that design fails as its moment of resistance comes out less than applied moment. A second approach is discussed for determining thickness and area of reinforcement in order to make it safe.

In the same numerical, area of reinforcement is calculated by reducing the thickness as obtained in second approach.

\section{Analysis and Design of Tank Wall}

Let us design the wall of the water tank subjected to bending moment $50 \mathrm{kNm}$ using M-30 concrete and Fe-415 steel.

First Approach: Following procedure is adopted to design the wall of the water tank in books -

Modular Ratio $(\mathrm{m})=\frac{280}{\mathrm{agcb} e}=\frac{280}{\mathrm{a} * 10}=9.33$

Neutral axis depth factor $(\mathrm{k})=\frac{\text { mocbe }}{\text { mocbe }+\sigma s t}=\frac{9.9 a * 10}{9 . a a * 10+130}$ 


\section{International Journal of Science and Research (IJSR) \\ ISSN (Online): 2319-7064}

Index Copernicus Value (2015): 78.96 | Impact Factor (2015): 6.391

$$
=0.418
$$

Lever arm factor $(\mathrm{j})=1-\mathrm{k} / 3=1-0.418 / 3=0.861$

Moment of resistance factor $(\mathrm{R})=\frac{1}{2} \sigma c b c k j$

$=\frac{1}{2} * 10 * 0.418 * 0.861=1.8 \mathrm{~N} / \mathrm{mm}^{2}$

Required effective depth of wall (d) $=\sqrt{\frac{M}{R b}}=\sqrt{\frac{50 * 10^{M} 6}{1.9 * 1000}}$ $=166.67$ say $170 \mathrm{~mm}$

Assume effective cover as $60 \mathrm{~mm}$.

Thickness of wall $(\mathrm{t})=170+60=230 \mathrm{~mm}$

Required area of reinforcement (Ast) $=\frac{50 * 10^{n} 6}{130 * 0.861 * 170}$

$$
=2627.70 \mathrm{~mm}^{2}
$$

Now let us calculate the moment carrying capacity of wall section

The moment carrying capacity of wall is calculated by considering following two cases and lesser is adopted as moment carrying capacity of the section.

Case-I: Considering cracked section

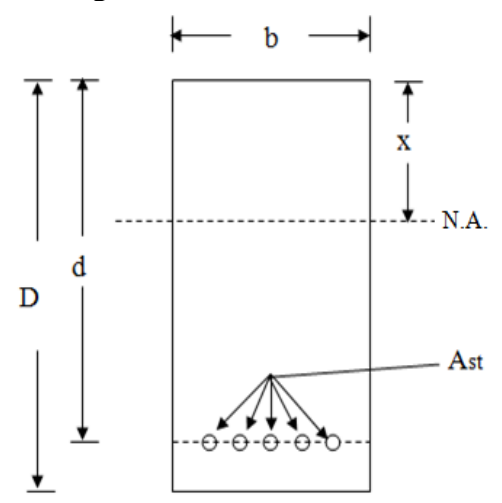

Figure 1: Cross section of cracked section

Depth of neutral axis

b x x/2 = m Ast (d-x)

$1000 * x^{2} / 2=9.33 * 2627.70 *(170-x)$

$\mathrm{x}=70.02 \mathrm{~mm}$

Depth of critical neutral axis

$\mathrm{xc}=\mathrm{k} * \mathrm{~d}=0.418 * 170=71.06 \mathrm{~mm}$

Since $\mathrm{x}<\mathrm{x}_{\mathrm{c}}$, hence section is under reinforced.

Moment considering cracked section

$(\mathrm{Mcr})=\mathrm{Ast} * \sigma \mathrm{st} *\left(\mathrm{~d}-\frac{x}{2}\right)$

$=2627.70 * 130 *(170-70.02 / 3)$

$=50.10 * 10^{\wedge} 6 \mathrm{Nmm}=50.10 \mathrm{kNm}----(\mathrm{i})$

Case-II: Considering uncracked section

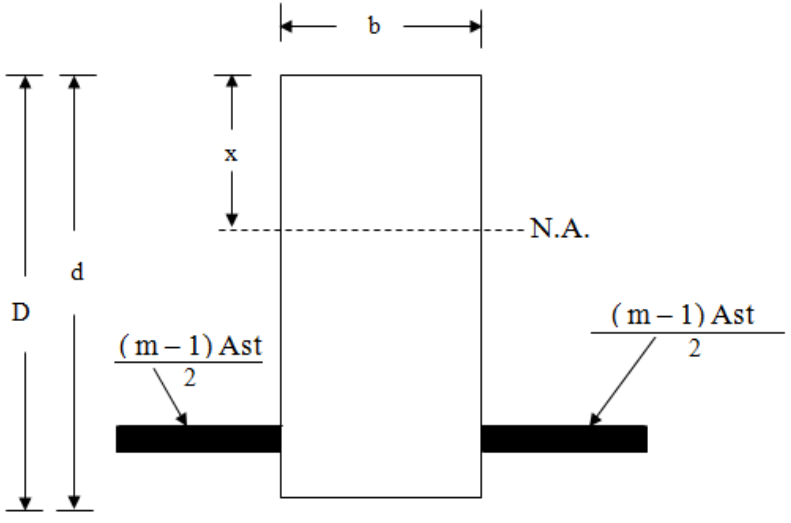

Figure 2: Cross section of uncracked section
Area of Transformed section

$$
\begin{aligned}
\left(\mathrm{A}_{\mathrm{T}}\right) & =\mathrm{bD}+(\mathrm{m}-1) \text { Ast } \\
& =1000 * 230+(9.33-1)^{*} 2627.70 \\
& =251888.74 \mathrm{~mm}^{2}
\end{aligned}
$$

Depth of neutral axis

$$
\begin{aligned}
\mathrm{X} & =\frac{b D \frac{D}{2}+(\mathrm{m}-1) \text { Ast } d}{A T}= \\
& =\frac{1000 \cdot 230 \cdot \frac{230}{2}+(9.8 \mathrm{a}-1) \cdot 2627.70 \cdot 170}{251889.74} \\
& =119.78 \mathrm{~mm}
\end{aligned}
$$

Moment of inertia of Transformed section about N.A.

$$
\begin{aligned}
\mathrm{I}_{\mathrm{T}}= & \frac{b x^{3}}{a}+\frac{b(\mathrm{D}-\mathrm{x})^{3}}{a}+(\mathrm{m}-1) \text { Ast }(\mathrm{d}-\mathrm{x})^{2} \\
= & \frac{1000 * 119.7 \mathrm{~g}^{n a} \mathrm{a}}{a}+\frac{1000 *(230-119.79)^{n a}}{a} \\
& +(9.33-1)^{*} 2627.70(170-119.78)^{2} \\
= & 1074376263 \mathrm{~mm}^{4}
\end{aligned}
$$

Moment considering cracked section

$$
\begin{aligned}
\text { Muncr } & =\frac{U T}{(D-x)} * \sigma \mathrm{cbt} \\
& =\frac{107427626 \mathrm{~g}}{(230-119.79)} * 2 \\
& =19.50^{\wedge} 10^{\wedge} 6 \mathrm{~N}-\mathrm{mm}=19.50 \mathrm{kNm}---(\mathrm{ii}) \\
& =\text { Least in }(\mathrm{i}) \text { and }(\mathrm{ii}) \\
& =19.50 \mathrm{kNm}<\text { Applied moment }(=50 \mathrm{kNm})
\end{aligned}
$$

Hence moment carrying capacity

Hence design is not safe.

Second Approach: To overcome this problem, the thickness of wall of tank is calculated from theory of uncracked section and then amount of reinforcement is calculated using theory of cracked section. Moment of resistance of a uncracked section ignoring the area of reinforcement is calculated by following formula-

$$
\mathrm{M}=\frac{\mathrm{I}}{\mathrm{y}_{\max }} \sigma_{\mathrm{cbt}}:
$$

where $\quad \mathrm{I}=$ M.I.of the section about N.A. ignoring area of reinforcement

$$
=\frac{\mathrm{bt}^{3}}{12}
$$

$\mathrm{y}_{\max }=$ Distance of extreme tension fibre from N.A. $=\mathrm{t} / 2$ $\sigma_{\mathrm{cbt}}=$ Permissible tensile stress in concrete in bending $=2 \mathrm{~N} / \mathrm{mm}^{2}$ for $\mathrm{M}-30$

$$
\begin{gathered}
\mathrm{M}=\frac{\mathrm{bt}^{2}}{6} \sigma_{\mathrm{cbt}} \\
\mathrm{OR} \mathrm{t}=\sqrt{\frac{6 M}{\mathrm{~b} * \sigma \mathrm{cbt}}}=\sqrt{\frac{6 * 50 * 10^{\Omega} 6}{1000 * 2}}
\end{gathered}
$$

$=387.29 \mathrm{~mm}$ say $390 \mathrm{~mm}$

Assume effective cover as $60 \mathrm{~mm}$.

Available effective depth $(\mathrm{d})=390-60=330 \mathrm{~mm}$

Required area of reinforcement (Ast) $=\frac{50 * 10^{36} 6}{130 * 0.861 * 930}$

$=1353.66 \mathrm{~mm}^{2}$

Moment of resistance of cracked section

$=53.41 \mathrm{kNm}$

Moment of resistance of uncracked section

$=53.80 \mathrm{kNm}$----- (ii)

Hence moment carrying capacity

$=$ Least in (i) and (ii)

$=53.41 \mathrm{kNm}>$ Applied moment $(=50 \mathrm{kNm})$

Hence design is safe. 


\section{International Journal of Science and Research (IJSR) \\ ISSN (Online): 2319-7064}

Index Copernicus Value (2015): 78.96 | Impact Factor (2015): 6.391

\section{Effect on Area of Reinforcement due to Reduction in Thickness of Wall}

Let us see the effect on area of reinforcement due to reduction in thickness of wall as calculated in second approach.

Assume thickness of wall as $370 \mathrm{~mm}$.

Effective depth (d) $370-60=310 \mathrm{~mm}$

Required area of reinforcement (Ast) $=\frac{50 * 10^{4} 6}{130 * 0.861 * 310}$

$$
=1440.99 \mathrm{~mm}^{2}
$$

Moment of resistance of cracked section

$$
=53.15 \mathrm{kNm}
$$

Moment of resistance of uncracked section

$$
=48.63 \mathrm{kNm}
$$

Hence moment carrying capacity

$$
\begin{aligned}
& =\text { Least in (i) and (ii) } \\
& =48.63 \mathrm{kNm}<\text { Applied moment }(=50 \mathrm{kNm})
\end{aligned}
$$

Hence design is not safe.

In order to make it safe, area of reinforcement must be increased. There is no direct approach for calculating the area of reinforcement in uncracked theory. It may be calculated by trial and error by using the following formulae

$$
\begin{aligned}
& \mathrm{A}_{\mathrm{T}}=\mathrm{bD}+(\mathrm{m}-1) \text { Ast } \\
& \mathrm{x}=\frac{b D \frac{D}{2}+(\mathrm{m}-1) \text { Ast } d}{A T} \\
& \mathrm{I}_{\mathrm{T}}=\frac{b \mathrm{x}^{3}}{\mathrm{a}}+\frac{b_{(\mathrm{D}-\mathrm{x})^{3}}}{\mathrm{a}}+(\mathrm{m}-1) \text { Ast }(\mathrm{d}-\mathrm{x})^{2} \\
& \mathrm{M}=\frac{{ }_{d T}}{(D-x)} * \sigma \mathrm{cbt}
\end{aligned}
$$

Required area of reinforcement (Ast) $=2115 \mathrm{~mm}^{2}$

Moment of resistance of cracked section

$$
=76.45 \mathrm{kNm}
$$

Moment of resistance of uncracked section

$$
=50.01 \mathrm{kNm}
$$

Hence moment carrying capacity

$$
\begin{aligned}
& =\text { Least in (i) and (ii) } \\
& =50.01 \mathrm{kNm}>\text { Applied moment }(=50 \mathrm{kNm})
\end{aligned}
$$

Hence design is safe.

Similarly area of reinforcement is calculated for other thickness $360 \mathrm{~mm}$ and $350 \mathrm{~mm}$ and tabulated in Table-2

\section{Discussion}

The results of first and second approach are given in Table -1

TABLE - 1 (Moment of Resistance of wall section)

\begin{tabular}{|c|c|c|c|c|c|c|}
\hline & $\mathrm{M}$ & $\mathrm{t}$ & Ast & Muncr & Mcr & M.R. \\
\hline & $(\mathrm{kN}-\mathrm{m})$ & $\mathrm{mm})$ & $\left(\mathrm{mm}^{2}\right)$ & $(\mathrm{kN}-\mathrm{m})$ & $(\mathrm{kN}-\mathrm{m})$ & $(\mathrm{kN}-\mathrm{m})$ \\
\hline $\begin{array}{c}\text { First } \\
\text { Approach }\end{array}$ & 50 & 230 & 2627.70 & 19.50 & 50.10 & 19.50 \\
\hline $\begin{array}{c}\text { Second } \\
\text { Approach }\end{array}$ & 50 & 390 & 1353.66 & 53.80 & 53.41 & 53.41 \\
\hline
\end{tabular}

It is clear from table-1 that second approach is correct as moment of resistance obtained is more than the applied moment.
Table 2: Area of reinforcement in wall section

\begin{tabular}{|c|c|c|c|c|c|}
\hline $\begin{array}{c}\text { Bending } \\
\text { Moment } \\
(\mathrm{M})\end{array}$ & $\begin{array}{c}\text { Thickness } \\
\text { of wall (t) }\end{array}$ & $\begin{array}{c}\text { Effective } \\
\text { depth of } \\
\text { wall(d) }\end{array}$ & $\begin{array}{c}\text { Required area } \\
\text { of } \\
\text { reinforcement } \\
\text { (Ast) }\end{array}$ & $\begin{array}{c}\% \\
\text { decrease } \\
\text { in } \\
\text { thickness } \\
\text { of wall }\end{array}$ & $\begin{array}{c}\% \\
\text { increase } \\
\text { in area of } \\
\text { reinforce } \\
\text {-ment }\end{array}$ \\
\hline $\mathrm{kN}-\mathrm{m}$ & $\mathrm{mm}$ & $\mathrm{mm}$ & $\mathrm{mm}^{2}$ & & \\
\hline 50 & 390 & 330 & 1353.66 & & \\
\hline 50 & 370 & 310 & 2115 & 5.13 & 56.24 \\
\hline 50 & 360 & 300 & 3495 & 7.69 & 158.19 \\
\hline 50 & 350 & 290 & 5030 & 10.26 & 271.59 \\
\hline
\end{tabular}

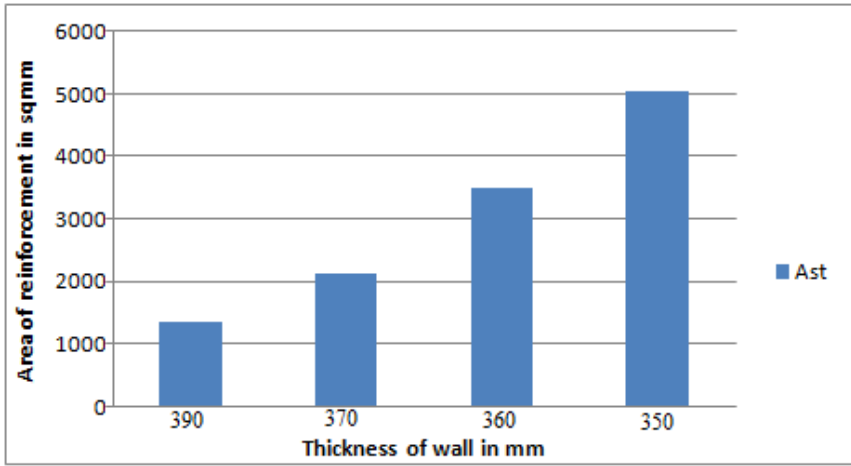

Graph 1: Variation in area of rainforcement

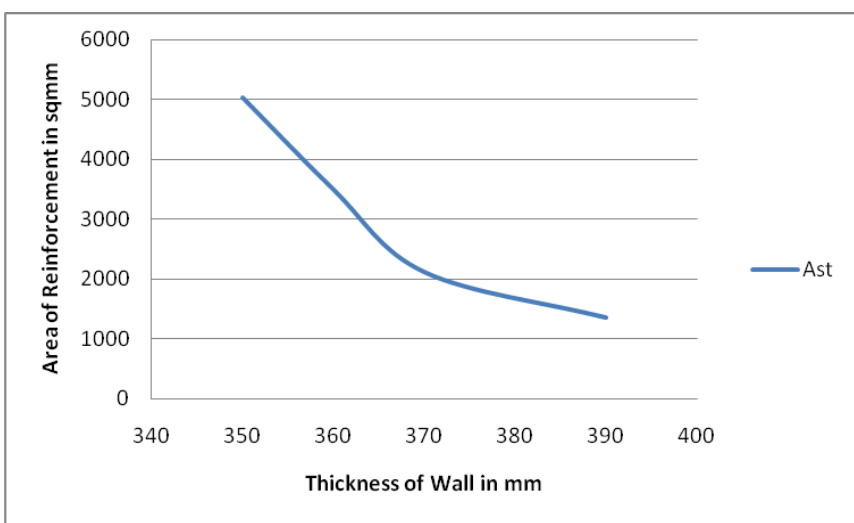

Graph 2: Variation in area of rainforcement

From table -2 , it is clear that if thickness is reduced by 5.13 $\%$, the area of reinforcement increases by $56.24 \%$.Similarly, If the thickness is reduced by $7.69 \%$ and $10.26 \%$, the corresponding increase in area of reinforcement is $158.19 \%$ and $271.59 \%$ respectively. Also, it is clear from Graph-2 that rate of $\%$ increase in area of reinforcement increases rapidly as thickness of wall goes on reducing. Hence, a small decrease in thickness requires large amount of reinforcement which makes the design uneconomical.

\section{Conclusion}

From the above results, following conclusions are extracted-

1) The second approach is logically correct.

2) The thickness of wall of water tank should be selected carefully otherwise section may be uneconomical

\section{References}

[1] Dayaratnam P. Design of Reinforced Concrete Structures. New Delhi. Oxford \& IBH publication.2000 
[2] Vazirani \& Ratwani. Concrete Structures. New Delhi. Khanna Publishers.1990.

[3] Sayal \& Goel .Reinforced Concrete Structures. New Delhi. S.Chand publication.2004.

[4] N.Krishna Raju, Advanced Reinforced Concrete Structures , CBS Publishers New Delhi $\underline{\text { CBS }}$ Publishers 2013

[5] Bhavikatti.V, Advanced Reinforced Concrete Design (vol-II), New age international, 2nd edition, 2009.

[6] O.P Jain and Jai Krishna Plain and reinforced Concrete Volume-II.

[7] Dr. B.C.Punmia, et al, Comprehensive R.C.C. Desings, Laxmi Pub. 1998.

[8] IS : 3370 ( Part I )- 2009, Code of Practice for Concrete Structures for the Storage of Liquids

[9] IS : 3370 ( Part II )- 2009, Code of Practice for Concrete Structures for the Storage of Liquids

\section{Author Profile}

Gajendra Verma obtained the Bachelor degree in Civil Engineering and Master Degree in Structural Engineering from Government Engineering College, Ujjain, Madhya Pradesh (India) in 1987 and 2010 respectively. He served the various Engineering Colleges. Currently he is working as an Associate Professor and HOD in the Department of Civil Engineering, Aurobindo Institute of Technology, Indore Madhya Pradesh (India). He has over two decades of teaching experience. His research interest is in the area of Structural designs. He is also a Member of Institute of Engineers and Indian Society for Technical Education. 